BMC

Evolutionary Biology

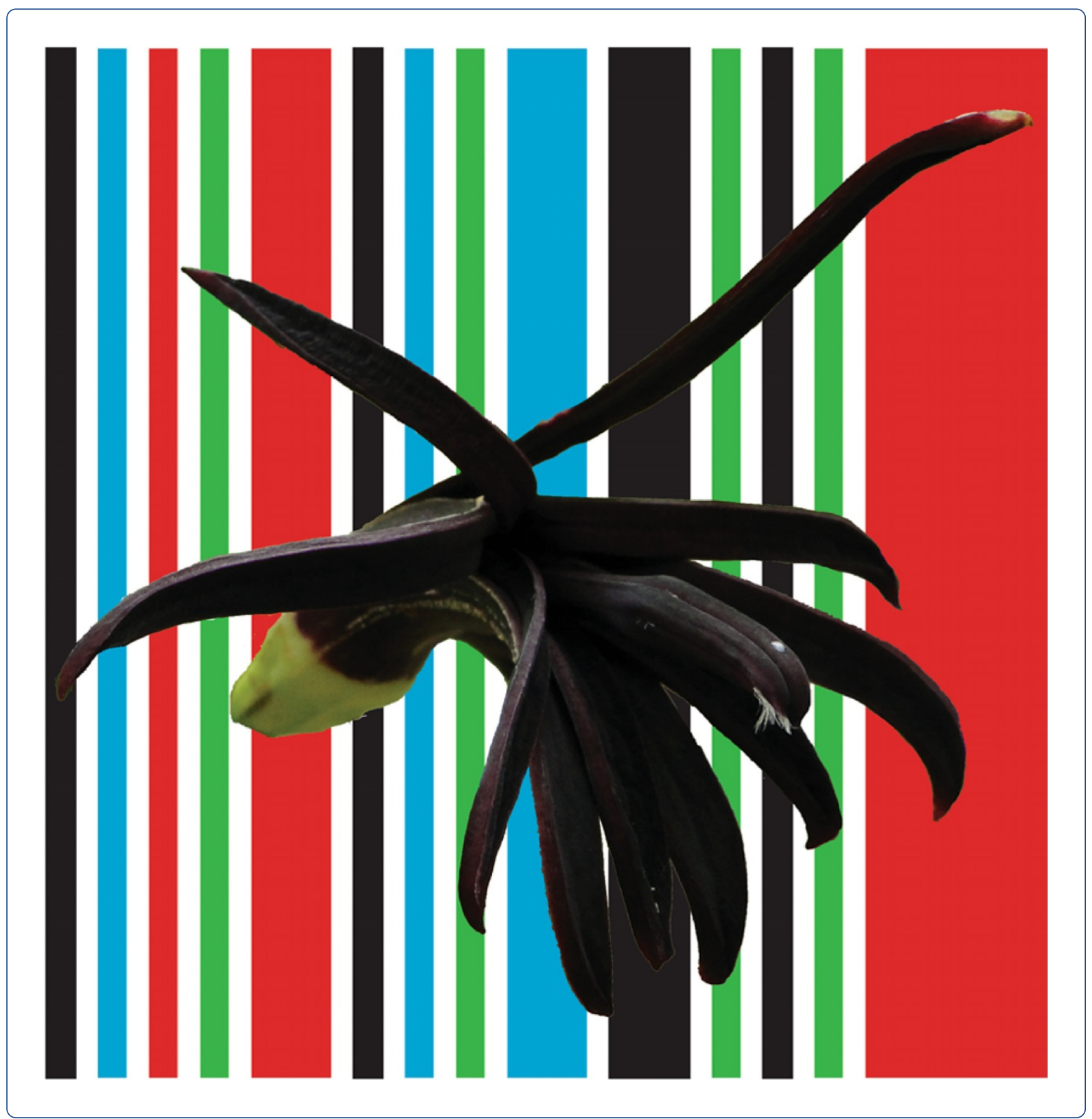

Potential use of low-copy nuclear genes in DNA barcoding: a comparison with plastid genes in two Hawaiian plant radiations

pillon et al. 


\title{
Potential use of low-copy nuclear genes in DNA barcoding: a comparison with plastid genes in two Hawaiian plant radiations
}

Yohan Pillon ${ }^{1 *}$, Jennifer Johansen ${ }^{1}$, Tomoko Sakishima', Srikar Chamala 2,3 , W Brad Barbazuk ${ }^{2,3}$, Eric H Roalson ${ }^{4}$, Donald K Price ${ }^{1}$ and Elizabeth A Stacy ${ }^{1}$

\begin{abstract}
Background: DNA barcoding of land plants has relied traditionally on a small number of markers from the plastid genome. In contrast, low-copy nuclear genes have received little attention as DNA barcodes because of the absence of universal primers for PCR amplification.

Results: From pooled-species 454 transcriptome data we identified two variable intron-less nuclear loci for each of two species-rich genera of the Hawaiian flora: Clermontia (Campanulaceae) and Cyrtandra (Gesneriaceae) and compared their utility as DNA barcodes with that of plastid genes. We found that nuclear genes showed an overall greater variability, but also displayed a high level of heterozygosity, intraspecific variation, and retention of ancient alleles. Thus, nuclear genes displayed fewer species-diagnostic haplotypes compared to plastid genes and no interspecies gaps.

Conclusions: The apparently greater coalescence times of nuclear genes are likely to limit their utility as barcodes, as only a small proportion of their alleles were fixed and unique to individual species. In both groups, species-diagnostic markers from either genome were scarce on the youngest island; a minimum age of ca. two million years may be needed for a species flock to be barcoded. For young plant groups, nuclear genes may not be a superior alternative to slowly evolving plastid genes.
\end{abstract}

Keywords: Adaptive radiation, Island biogeography, Lobeliads, Next-generation sequencing, Progression rule, Single-copy nuclear genes

\section{Background}

DNA barcoding is a recent technique that employs one or a few short, universal DNA regions to place sampled individuals into named species and to identify individuals as belonging to putatively undescribed species (http://www.barcodeoflife.org/). DNA-based identification promises a range of applications, including identification of organisms at cryptic life stages (e.g., seeds, seedlings, larvae), source identification of plant or animal parts (e.g., plant foodstuffs, herbal medicines, meats and furs from CITES-protected species), forensics, and surveys

\footnotetext{
* Correspondence: pillon@hawaii.edu

${ }^{1}$ Tropical Conservation Biology and Environmental Science, University of

Hawai'i at Hilo, 200 West Kawili Street, Hilo, HI 96720, USA

Full list of author information is available at the end of the article
}

of poorly known biological communities e.g., tropical rainforests, deep-sea communities, microbial communities [1].

Although DNA barcoding of animals using mitochondrial genes has been done with high success [2], plants have proven to be somewhat recalcitrant to DNA barcoding. The low sequence variation in the plant mitochondrial genome has led to a search for alternative universal DNA barcodes for plants, which has proven difficult [3]. Most genes tested as universal plant DNA barcodes are within the plastid genome, and a small number of them are becoming increasingly popular [4]. A single gene is unlikely to provide enough resolution to differentiate all plant species [5], yet six plastid genes in combination still fail to discriminate all species within the genus Crocus [6]. Other candidates include nuclear ribosomal genes [7]; however, their utility as

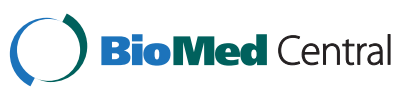


DNA barcodes may be limited by incomplete concerted evolution, fungal contamination, and amplification failure [3]. Although DNA barcoding using multiple genes has proven successful with high resolution for phylogenetically diverse communities, e.g., Panamian trees (98\% species discrimination, [8]), Mesoamerican orchids and Kruger National Park trees (> 90\% species identification, [9]), but see Gonzalez et al. ( $<70 \%$ species identification, [10] for Amazonian trees), barcoding studies of single clades have had limited success, e.g., 43.5\% species discriminated in Bromeliaceae [11], and 32\% in Fraxinus [12]. Alternative candidates for DNA barcodes are low-copy nuclear genes, which have received little attention (i.e., [13]). Problems expected with such genes include the design of universal primers, gene duplications, recombination, allopolyploidy and heterozygosity [3].

The native flora of Hawai'i boasts extreme endemism (89\% for angiosperms [14]) and offers a unique opportunity to evaluate DNA barcoding on species and communities of different ages. The Hawaiian flora is a rich but young assemblage, with the majority of lineages originating on the main islands within the past five million years [15]. Hawaii's main islands are part of a broader volcanic chain and span a natural age gradient from 0.5 to 5 my [15]. Although many of Hawaii's endemic plant lineages span the main islands, most species are restricted to a single island [16], and their maximum ages can be set to the age of the island on which they occur. As such, the Hawaiian flora allows estimation of a species-age or a community-age threshold below which DNA barcoding fails to delineate species.

To our knowledge, DNA barcoding has not been attempted on the Hawaiian flora, and, plastid genes (the most popular DNA barcodes) have comparatively been little used for phylogenetic studies of Hawaiian radiations, presumably due to a near absence of variation in these genes. Instead, most studies have used ribosomal genes [17-21] or in a few cases low-copy nuclear genes $[22,23]$, finding moderate levels of variation at these genes. One of the notable exceptions is the phylogeographic study of Metrosideros by Percy et al. [24] based on 10 plastid genes; nonetheless, these genes failed to fully resolve the evolutionary history of the genus within the Hawaiian Islands. The availability of DNA barcodes for the Hawaiian flora is particularly desirable as many native species are difficult to distinguish through vegetative characters alone, many are threatened by extinction, and hybridization appears to be common.

Our study focused on two plant genera of the Hawaiian Islands: Clermontia (Campanulaceae) and Cyrtandra (Gesneriaceae). Clermontia is an endemic genus of rainforest shrubs that are either epiphytic or terrestrial with bird-pollinated flowers that show great variation in flower morphology among species. The genus belongs to the Hawaiian lobeliads, the largest Hawaiian radiation [25], and comprises 22 species [14], most of which are found on the youngest islands of Maui and Hawai'i (Big Island). Cyrtandra is a genus of understorey shrubs with somewhat uniform, white and probably insect-pollinated flowers and great variation in vegetative characters, although the adaptive significance of the latter is generally not clear. The genus comprises 53 species [14], all endemic, more or less evenly distributed among the main islands, with O'ahu having the greatest diversity. In both genera, most species are restricted to a single island, and numerous cases of hybridization have been reported. Furthermore, circumscription of species with multipleisland distributions is often disputed. The estimated crown ages for Clermontia and Hawaiian Cyrtandra are 3.2 My [25] and 5.2 My [26], respectively.

In this study, we evaluate the potential of low-copy nuclear genes as DNA barcodes in Clermontia and Cyrtandra, and discuss some of their advantages and disadvantages compared to frequently used plastid genes. We did not attempt to identify universal barcodes, but rather conducted a pilot study to see how such markers would be informative.

\section{Results}

Variation within single-copy nuclear genes vs. plastid genes Although relatively short in length, the nuclear genes generally exhibited a greater number of variable sites than plastid genes and had a percentage of variable sites up to several fold that of plastid genes (Tables 1 \& 2). Heterozygosity was common in nuclear genes (Additional files 1 \& 2): $25 \%$ of the individuals at Clerm2, $5.5 \%$ at Clerm4, $34.4 \%$ at Cyrt2 and $36.1 \%$ at Cyrt4. Accumulation curves (Figures 1 and 2) for plastid genes showed that in both genera, a plateau was reached and that most of the haplotype diversity present in each group was captured in our study. In contrast, with the exception of Clerm4 which was especially short $(172 \mathrm{bp})$, the slopes of the nuclear haplotype accumulation curves showed no inflexion, indicating that many more haplotypes could be found with further sampling. Limited variation and especially low numbers of differences between haplotypes did not allow detection of recombination in any nuclear genes.

In Clermontia, where haplotype networks for plastid and nuclear genes could be contrasted (i.e., haplotypes were available for two genes of each type), networks differed in their structure (Figure 3). With a minor exception, the plastid gene networks for Clermontia were strictly linear $(I=0$, Table 1$)$, whereas the network for Clerm2 was star-like with the occurrence of loops. The network for the short nuclear gene, Clerm4, had only five haplotypes and was neither strictly linear nor starlike (Figure 3). Ramification indices for the two nuclear 
Table 1 Variability and properties of the markers (three plastid, two nuclear) used in Clermontia

\begin{tabular}{lllllll}
\hline & rbcL & psbA-trnH & matK & Combined plastid & Clerm2 & Clerm4 \\
\hline Length, excluding primers & 533 & 439 & $837-858$ & $1829-1850$ & 556 & 172 \\
Number of variable sites (number of indels) & 5 & 5 & $4(1)$ & $14(1)$ & 3 \\
Percent of variable sites, excluding indels & 0.90 & 1.14 & 0.005 & 0.008 & 10 & 1.80 \\
Percent of "ghost" haplotypes & 16.7 & 16.7 & 16.7 & 56.3 & 0 & 0 \\
Ramification index & 0 & 0.2 & 0 & 0.13 & 0.58 \\
\hline
\end{tabular}

"Ghost" alleles are intermediate alleles that were not recovered in any of the accessions sampled. The ramification index (I) was calculated as follows: I= 1 - (longest distance between two haplotypes/total length of the network).

gene networks were greater than those for the three plastid genes. Each plastid gene network contained a single intermediate haplotype that was not recovered in any accession ("ghost" haplotype); there was no such haplotype in the nuclear datasets. For Cyrtandra, the single plastid gene and two nuclear genes showed highly ramified haplotype networks (Figure 4), but the ramification indexes indicated a greater degree of reticulation in the networks of the two nuclear genes compared to the plastid gene. There was one ghost haplotype (out of 9) in the plastid network, none in the nuclear Cyrt2 network, and two (out of 21) in the Cyrt4 network.

\section{Taxonomic distribution of genetic diversity}

For Clermontia, the plastid and nuclear genes revealed species-diagnostic haplotypes (here defined as haplotypes unique to a single species and found in all individuals of that species) for $18 \%$ and $12 \%$ of the sampled taxa, respectively. Each of the three plastid genes had two species-diagnostic haplotypes, and the combined dataset produced diagnostic haplotypes for three species: Cl. fauriei (Kaua'i), Cl. oblongifolia (O'ahu) and Cl. kakeana (O'ahu and Maui; figure five). In nuclear genes, Clerm2 yielded a single species-diagnostic haplotype for $\mathrm{Cl}$. fauriei, and Clerm4 a single speciesdiagnostic haplotype for $\mathrm{Cl}$. oblongifolia. Several species possessed multiple haplotypes for a given nuclear gene, with up to six in C. arborescens for Clerm2. Speciesdiagnostic haplotypes that differ by more than one substitution from others (i.e., interspecific gap) were found only

Table 2 Variability and properties of the markers used in Cyrtandra

\begin{tabular}{llll}
\hline & psbA-trnH & Cyrt2 & Cyrt4 \\
\hline Length, excluding primers & $388-403$ & 314 & 291 \\
Number of variable sites (number of indels) & $5(2)$ & 19 & 21 \\
Percent of variable sites, excluding indels & 1.29 & 6.05 & 7.21 \\
Percent of "ghost" haplotypes & 11.1 & 0 & 10 \\
Ramification index & 0.5 & 0.66 & 0.61 \\
\hline
\end{tabular}

"Ghost" alleles are intermediate alleles that were not recovered in any of the accessions sampled. The ramification index (I) was calculated as follows: I=1 (longest distance between two haplotypes/total length of the network). for $\mathrm{Cl}$. fauriei and $\mathrm{Cl}$. oblongifolia in the combined plastid dataset. Conflicts were present in the genetic identity of $\mathrm{Cl}$. singuliflora; this species grouped with $\mathrm{Cl}$. peleana in the plastid dataset but was closer to $\mathrm{Cl}$. parviflora and allies in the nuclear datasets.

For Cyrtandra, the plastid and nuclear genes revealed species-diagnostic haplotypes for $20 \%$ and $10 \%$ of the sampled taxa, respectively. The psbA-trnH dataset yielded diagnostic haplotypes for four species: Cy. longifolia (Kauai), Cy. wawrae (Kaua'i), Cy. lydgatei (Maui) and Cy. paludosa (Kaua'i, O'ahu and Hawai'i; figure six). In contrast, the nuclear Cyrt2 gene revealed just one species-diagnostic haplotype (Cy. longifolia), and the Cyrt4 gene revealed diagnostic haplotypes for Cy. grayi (Maui), that were not distinguished by either of the above markers. Only Cy. platyphylla had multiple plastid haplotypes (one on Maui and one on Hawai'i Island), whereas 12 species had multiple haplotypes in the Cyrt2 dataset and 9 in the Cyrt4 dataset. A species-diagnostic haplotype that differs by more than one substitution was found for just one species, Cy. longifolia, in the $p s b A$-trnH dataset.

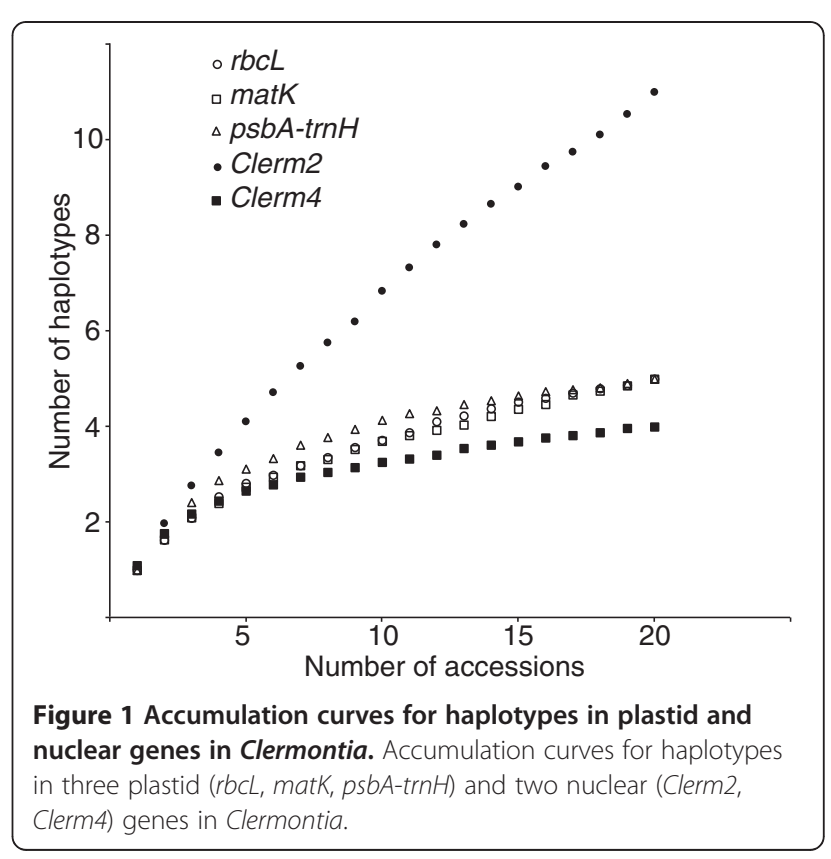




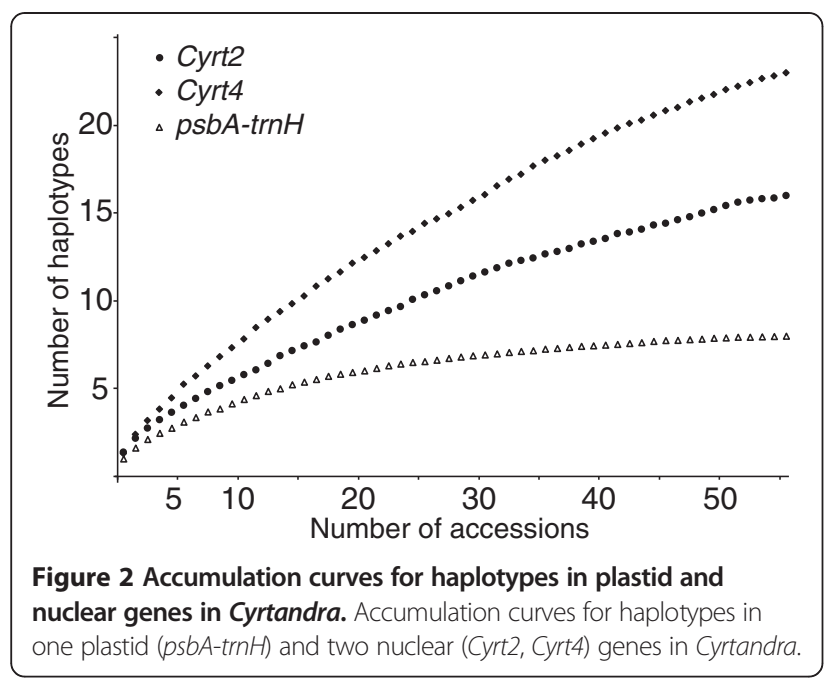

\section{Geographic distribution of haplotype diversity}

Across genes and genera, there appeared to be a positive relationship between haplotype diversity and island age (Additional file 3). In Clermontia, plastid haplotypes occurred on two islands at most, whereas some nuclear haplotypes were found on three islands. In Cyrtandra, for which haplotype variation was greater, there were several haplotypes at each of the three genes that occurred on three or four islands.

In contrast to the nuclear genes that showed almost no geographic structure, plastid gene networks aligned to a high (Clermontia) or low (Cyrtandra) degree with the geographic order of islands (Figures 5 \& 6). In plastid gene networks for Clermontia, haplotypes from Kauai were on one end, and haplotypes from Hawai'i Island were generally on the other. In the psbA-trnH datast of Cyrtandra, the most isolated haplotype $(\mathrm{C})$ was from Kaua'i. In nuclear datasets in contrast, no geographic structure could be detected in the star-like networks in either genus; the nuclear genes generally possessed one or two common haplotypes that were found on multiple islands. Nevertheless, the branch bearing the haplotypes J, K and L of the Cyrt4 network was restricted to Kauaii. For both genera, the greatest resolution of species was possible for the oldest island of Kaua'i (e.g., Cl. fauriei was unique at multiple genes). Removing Kaua'i species from the analysis eliminated most of the observed geographical structure and almost all of the species-diagnostic markers.

\section{Discussion}

\section{Greater coalescence times in nuclear genes}

Despite their modest lengths, the nuclear genes examined in this study were highly variable relative to plastid genes, most likely due to their greater coalescence times. The short lengths of the nuclear regions (between 172 and $556 \mathrm{bp}$ ) resulted from the difficulty of finding genes with long exons that would allow direct sequencing in all accessions. Nevertheless, the high percentage of variable sites in these genes compared to plastid genes allowed detection of a greater number of haplotypes. Furthermore, the lack of plateau in the accumulation curves for three of the four nuclear genes indicated that a significant number of haplotypes were not captured in our samples.

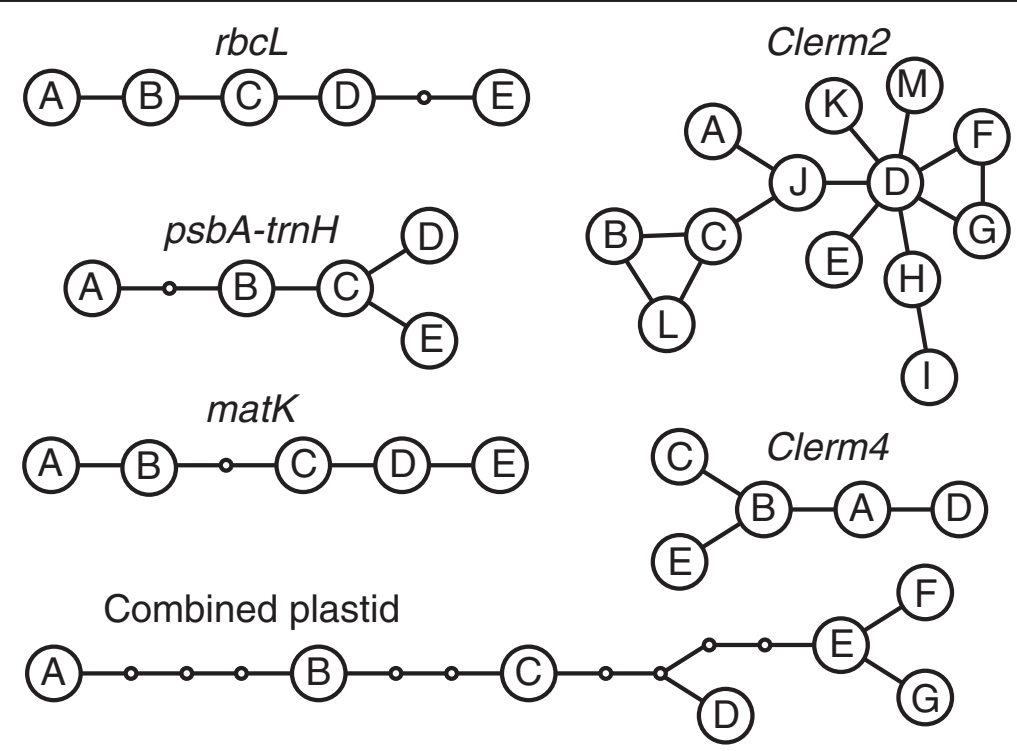

Figure 3 Haplotype networks for plastid and nuclear genes in Clermontia. Haplotype networks for plastid (rbcL, matK, psbA-trnH) and nuclear (Clerm2, Clerm4) genes in Clermontia. The small empty circles indicate "ghost" alleles (intermediate alleles that were not recovered in any of the accessions sampled). 


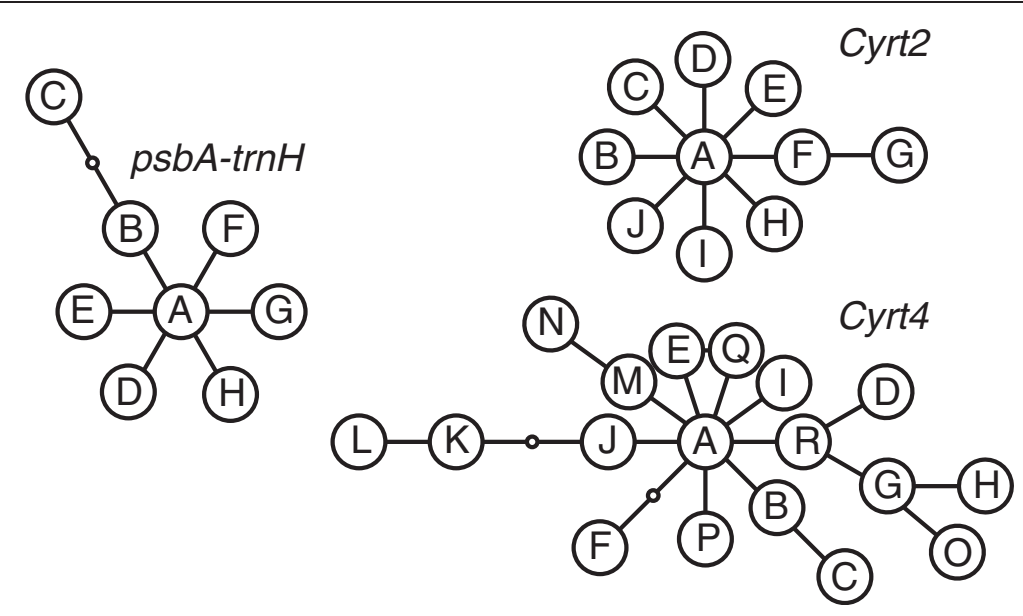

Figure 4 Haplotype networks for plastid and nuclear genes in Cyrtandra. Haplotype networks for plastid (psbA-trnH) and nuclear (Cyrt2, Cyrt4) genes in Cyrtandra. The small empty circles indicate "ghost" alleles (intermediate alleles that were not recovered in any of the accessions sampled).

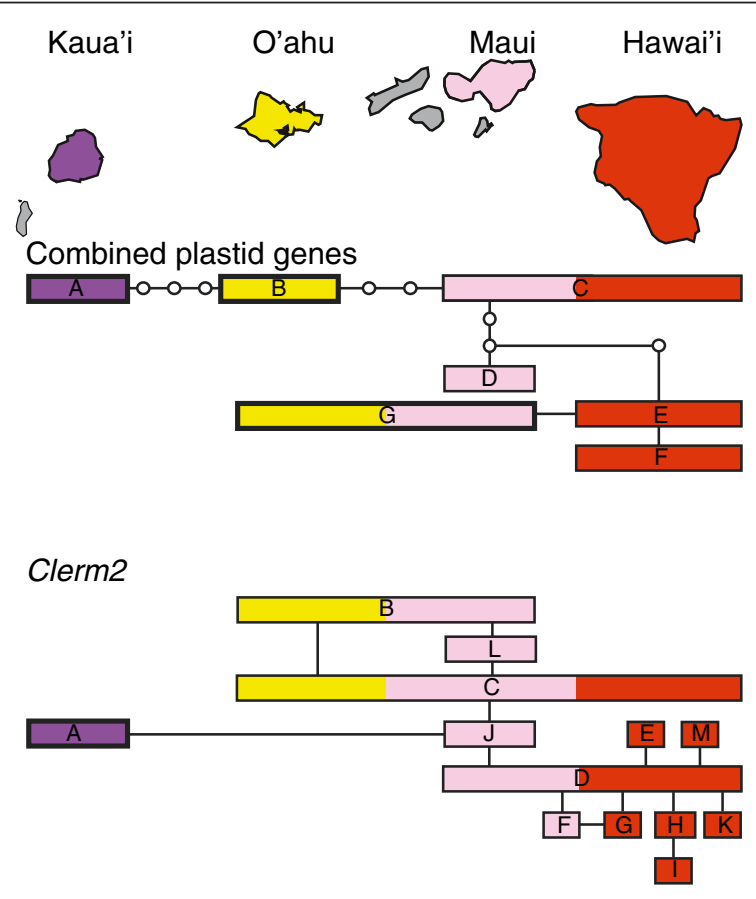

\section{Clermontia}
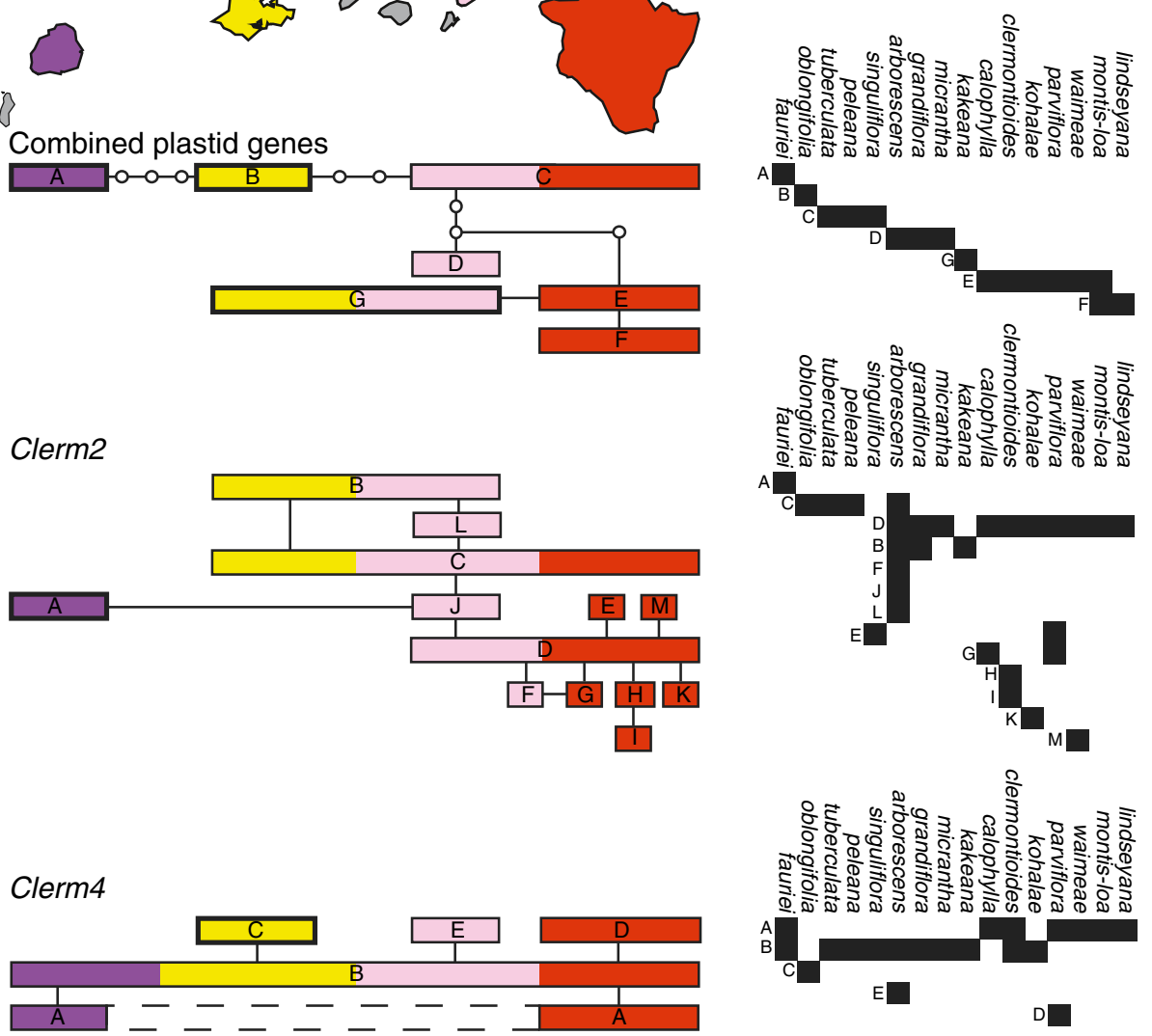

Figure 5 Geographic and taxonomic distributions of haplotypes in Clermontia. The combined plastid dataset includes data from rbcL, matK and psbA-trnH; Clerm2 and Clerm4 are two nuclear loci. The left-hand side shows the haplotype network and the geographical distribution of alleles. Empty circles indicate "ghost" alleles (intermediate alleles that were not recovered in any of the accessions sampled). Thickened rectangles indicate species-diagnostic haplotypes. The right-hand side shows the taxonomic distribution of the haplotypes. 


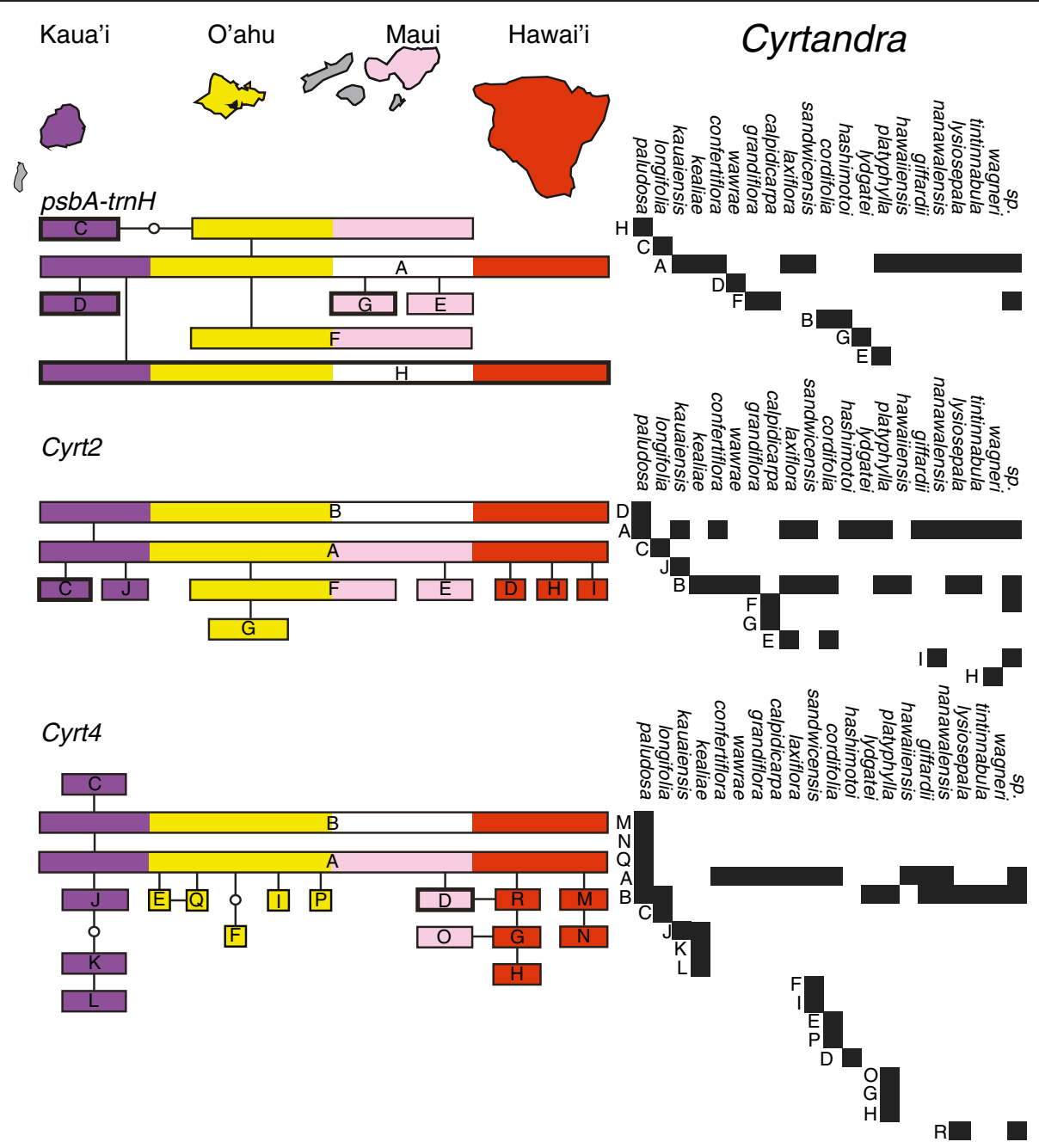

Figure 6 Geographic and taxonomic distributions of haplotypes in Cyrtandra. psbA-trnH is a plastid locus and Cyrt2 and Cyrt4 are two nuclear loci. The left-hand side shows the haplotype network and the geographical distribution of alleles. Empty circles indicate "ghost" alleles (intermediate alleles that were not recovered in any of the accessions sampled). Thickened rectangles indicate species-diagnostic haplotypes. The right-hand side shows the taxonomic distribution of the haplotypes.

The greater variability of nuclear loci and many other differences with plastid genes can be explained by the greater coalescence times of nuclear genes compared to organelle genes [27]. Because of the larger effective population sizes of nuclear genes (two alleles per individual) compared to plastid genes (a single allele per individual), genetic drift is less influential, ancestral haplotypes are maintained for longer periods of time, and fixation of novel mutations in nuclear genes requires longer time periods, perhaps three times as long as required for plastid genes [27]. In the nuclear genes examined in this study, ancestral haplotypes are still present at the centre of the star-like networks and are also often abundant and widespread across species, thus contributing to high intraspecific polymorphism. Particularly in Cyrtandra, high polymorphism was maintained in nuclear genes in many species, and the multiple alleles present are probably much older than their corresponding species or even the islands on which the species are found. Similarly, genetic diversity within islands was greater for nuclear genes relative to plastid genes, and the elapse time between the formation of two consecutive Hawaiian islands is probably too short to allow for the fixation of a single allele within each island. Thus, ancestral alleles are spread through these populations during colonization of new islands, resulting in the presence of several common nuclear haplotypes across the archipelago from Kaua' $i$ to Hawai'i. In plastid genes, in contrast, intraspecific polymorphism was rare. Rather, the plastid gene networks revealed that several intermediate haplotypes have been lost (particularly in Clermontia), most likely through drift. In summary, the comparison between nuclear and plastid genes reveals that the plastid genes possess a greater number of species-diagnostic 
haplotypes, some of which were distinct by more than one substitution, allowing delineation of a larger number of species with greater confidence.

\section{Is there a species-age threshold below which DNA barcoding fails?}

With its 5-million-year chronosequence of islands of known ages, large number of island-endemic species, and generally positive relationship between island age and species age within many taxonomic groups (i.e., the progression rule, [28]), Hawai'i offers a unique opportunity to examine the evolutionary timescale over which DNA barcoding works. The progression rule $[28,29]$ assumes that most native plant and animal lineages colonized Hawai'i by way of the oldest main island of Kaua'i (4.7 My, [15]), and then spread to each new island to the east as it formed: O'ahu (3.0 My), Maui nui (Maui, Molokai'i, Lana'i, 2.2 My) and finally Hawai'i (0.5 My).

Evidence for the progression rule in Clermontia is clear. A previous phylogenetic analysis based on plastid genes [25] suggested that the single Kaua'i species $\mathrm{Cl}$. fauriei is sister to all other Hawaiian Clermontia, and this same pattern was recovered with an extended sampling of genes and species (Y. Pillon et al. unpublished). Clermontia's putative sister group, Cyanea, also probably originated on Kaua'i [30]. Further, our combined plastid network revealed a linear distribution of haplotypes congruent with the progression rule, from one end to the other: Kaua'i, O'ahu and MauiHawai'i. Two independent colonizations of Hawai $i$ from Maui are indicated, and the single haplotype of Clermontia kakeana (O'ahu, Maui nui), is nested within a clade from Hawai' $i$, thus indicating westward migration between islands. This combined evidence strongly indicates that Clermontia originated on Kaua' $i$ and then colonized the younger islands roughly in the order of their formation. The nuclear Clerm 2 gene network, despite its abundant reticulation and low divergence between haplotypes, is weakly consistent with the above pattern.

Although the progression rule is not clear in Cyrtandra [26], there are some lines of evidence that support an origin for this group on Kaua'i. All three genes revealed common haplotypes that were found on all islands. However, the most divergent haplotypes for both Cyrt4 and $p s b A-\operatorname{trn} H$ were found on Kaua'i. Furthermore, haplotype diversity increased with island ages (Additional file 3 ). Within all three genes, occurrence of several haplotypes across most or all islands suggests that each island has been colonized multiple times by Cyrtandra.

Both plant groups therefore appear to show at least a rough association between island age and species age, and this study revealed more species-diagnostic haplotypes on the oldest island of Kaua'i than on any other island. The single Clermontia species from Kaua'i, Cl. fauriei, was genetically distinct at five of six loci. Each of three Cyrtandra species from Kaua'i had a unique diagnostic haplotype in one or more markers: Cy. longifolia, Cy. paludosa and Cy. wawrae. When investigated with additional markers, all species of Cyrtandra on Kaua'i can be distinguished (Y. Pillon et al. unpublished). In contrast, no species endemic to the youngest island of Hawai'i had species-diagnostic markers. In most cases, species from this island displayed one of the common haplotypes, associated in some cases with one rare haplotype. Genetic diversity was not much greater on Kaua'i than on Hawai'i Island, but it seems that genetic drift has had more time to sort haplotypes among species on Kaua'i. In Cyrtandra, we did not find any species-diagnostic markers on the second-oldest island of O'ahu (albeit the most species rich) or Hawai'i, but found two species-diagnostic markers on Maui. Our sampling of Cyrtandra was most limited on this island, as we collected just three of the ten species there; it is highly possible therefore that sampling of additional species would eliminate some or all of the species-diagnostic markers from this young island. In Clermontia, in addition to the well differentiated Kaua'i species, C. fauriei, the two species sampled from O'ahu (Cl. oblongifolia and $\mathrm{Cl}$. kakeana), where the genus is poorly diversified, had species-diagnostic markers. On the younger islands, only $\mathrm{Cl}$. kakeana from Maui (but also O'ahu) could be identified through our markers, and none of Hawai'i Island's species could be distinguished. These results suggest that species from Maui and Hawai'i are still too young to be barcoded. There may be a threshold between 3 and 4.7 million years for Cyrtandra and between 2.2 and 3.0 million years for Clermontia below which species flocks are too young to be barcoded with the markers currently available.

\section{Conclusions}

A major issue preventing the use of low-copy nuclear genes in DNA barcoding has been the absence of universal primers to amplify genes over a large spectrum of plant taxa. Other issues that are less commonly considered include sequencing of accessions with multiple alleles of different lengths. Discerning alleles in these cases with the common Sanger method will require cloning and therefore a significant increase in cost and labor, although this issue may be circumvented in the future with new high throughput sequencing methods (e.g., [31]). Furthermore, multiple plastid regions are easily combined for analysis because each region has a single allele per individual and no recombination. Our examination of two low-copy nuclear genes for each of two Hawaiian plant genera and their comparison with classic barcoding genes from the plastid genome reveals 
another major issue for the use of nuclear genes in DNA barcoding: their longer coalescence times. The retention of ancient alleles in young species makes discovery of species-specific markers less likely with such genes in spite of their higher level of variability. Studies of more ancient groups are needed to determine whether this problem is restricted to young species radiations. Lastly, the greater variability of nuclear genes makes them desirable markers for phylogenetic studies, but the high frequency of heterozygotes and long coalescence times (which result in the shared retention of ancient alleles in many species) will likely limit their utility in analyses of closely related species.

\section{Methods}

As part of a parallel study involving the development of single-nucleotide polymorphism (SNP) markers, we obtained a pooled, partial transcriptome library from leaf and flower buds [fixed in RNA later (QIAGEN)] of nine taxa: Clermontia arborescens, Cl. clermontioides, Cl. fauriei, $\mathrm{Cl}$. kakeana, Cl. kohalae, Cl. parviflora $\mathrm{Cl}$. peleana, Cyrtandra longifolia and a hybrid Cy. hawaiiensis $\times$ calpidicarpa. RNA, cDNA synthesis and 454 sequencing were carried out at the University of Arizona Genetics Core Lab. 454 adapters, ribosomal RNA, low quality, and lowcomplexity sequences were removed/trimmed using SeqClean (http://compbio.dfci.harvard.edu/tgi/software/), and each taxon was assembled separately by the TGI Clustering tools (TGICL) [32]. We blasted our data against the 400 most highly expressed genes in Arabidopsis (C. Fizames, pers. comm.) in CLC DNA Workbench in order to optimize the probability of identifying a set of genes with high coverage in each of all or most species. We selected loci (generally only a small portion of a gene) that comprised a single, long exon (200 bp) with matches in multiple species, and designed primers with FastPCR for their amplification. The presence of introns was tested by comparison with genomic and cDNA sequences in Arabidopsis available at www.arabidopsis.org. Introns were avoided because preliminary work in both groups showed that introns commonly contained indels, which in the case of heterozygotes with alleles of different lengths prevented reading of direct sequences. After preliminary trials, two nuclear regions were selected for each genus based on ease of amplification and sequencing (absence of paralogs), and level of variation. We selected Clerm2 (putative homolog of At1g61520, PSI type III chlorophyll a/b-binding protein, Lhca3*1) and Clerm4 (At3g26520, gamma tonoplast intrinsic protein 2, TIP2) for Clermontia; Cyrt2 (At2g18020 embryo defective 2296, EMB2296/Ribosomal Protein L2) and Cyrt4 (At4g13940, S-Adenosyl-L-homocysteine hydrolase, SAHH) for Cyrtandra. These nuclear regions were amplified using the following mix: $12.3 \mu \mathrm{L}$ of $\mathrm{H}_{2} \mathrm{O}, 4$ $\mu \mathrm{L}$ of Gotaq $5 \times$ Buffer (PROMEGA), $2 \mu \mathrm{L}$ of $\mathrm{MgCl}_{2}$ $25 \mathrm{mM}, 0.4 \mu \mathrm{L}$ of dNTP $1.25 \mu \mathrm{M}, 0.2 \mu \mathrm{L}$ of each primer $10 \mu \mathrm{M}, 0.1 \mu \mathrm{L}$ of GoTaq Flexi DNA polymerase $5 \mathrm{u} / \mu \mathrm{L}$ (PROMEGA) and $0.8 \mu \mathrm{L}$ of DNA template. The following amplification program was used: $2^{\prime}$ at $94^{\circ} \mathrm{C}, 38$ cycles of $1^{\prime}$ at $94^{\circ} \mathrm{C}, 1^{\prime}$ at $61^{\circ} \mathrm{C}$ (for Cyrt2 and Cyrt4, $63^{\circ} \mathrm{C}$ for Clerm 2 and Clerm4), $1^{\prime}$ at $72^{\circ} \mathrm{C}$ and a final extension of $5^{\prime}$ at $72^{\circ} \mathrm{C}$.

To compare the utility of these nuclear genes and plastid genes as DNA barcodes, we sequenced the most universally accepted barcode loci for plants, mat $K$ and $r b c L$ and the most commonly suggested additional locus, psbA-trnH. In Cyrtandra, amplification of matK was difficult (failed or weak amplification), and direct sequences for $r b c L$ were often not clear because of the apparent presence of a pseudogene. The latter may result from a gene transfer to the nuclear or mitochondrial genome, a phenomenon that sometimes occur in angiosperms [33]. Therefore, only $p s b A-t r n H$ was sequenced in Cyrtandra.

We sequenced 26 populations of 17 species of Clermontia from Kaua'i, O'ahu, Maui and Hawai' $\mathrm{i}$ (Big Island), typically 4 accessions per population for each nuclear gene; C. kakeana was sampled on both Maui and O'ahu. We included 20 species of Cyrtandra from Kauai, O'ahu, Maui and Hawai'i, as well as a few undetermined plants (some possibly undescribed species). We sequenced two accessions from one population for each species; C. paludosa and C. platyphylla were represented by multiple populations on multiple islands. For plastid genes we also sequenced two accessions per population in Cyrtandra, but only a single accession per species in Clermontia because of the low variation observed. A larger scale genotyping study indicates that variation in plastid markers within Clermontia species is uncommon (Y. Pillon et al. unpublished data).

In heterozygous accessions, two haplotypes were determined by comparison with homozygotes following the procedure of Clark [34]; in a few cases the two haplotypes could not be determined. A network of haplotypes was built using the software TCS [35]. For each gene we determined a ramification index (I) to distinguish networks that were linear (no ramification; $I=0$ ) from those that were star-like (highly ramified; I close to 1). We used the following formula: $\mathrm{I}=1-$ (longest distance between two haplotypes/total length of the network).

\section{Additional files}

Additional file 1: Clermontia genotypes and DNA accessions. List of Clermontia accessions with geographical origin, voucher information, genotypes and GenBank accession numbers. 
Additional file 2: Cyrtandra genotypes and DNA accessions. List of Cyrtandra accessions with geographical origin, voucher information, genotypes and GenBank accession numbers.

Additional file 3: Genotypic diversty in Clermontia and Cyrtandra across Hawaiian islands after rarefaction.

\section{Competing interest}

The authors declare that they have no competing interests.

\section{Authors' contributions}

YP, DP and ES designed the study. JJ performed fieldwork, YP and TS performed molecular work, EHR, WBB and SR contributed data/analytical tools, YP and ES drafted the manuscript. All authors read and approved the final manuscript.

\section{Acknowledgments}

The authors wish to thank the following for facilitating the collection of plant specimens: Hawaii's DLNR-DOFAW, Maui Land \& Pineapple (Randi Bartlett), NARS (Betsy Gagne), The Nature Conservancy (Eldridge Naboa \& Pat Bily), Volcano Rare Plant Facility (Patty Moriyasu \& Jaime Enoka), Plant Extinction Prevention Program (Kealii Bio \& Hank Oppenheimer), Joel Lau, Kohala watershed Partnership (Melora Purell), Kahua Ranch, ParkerRanch and East Maui Irrigation, New Moon Foundation, and Grant Gerrish. We thank Michel Lebrun Cécile Fizames for information on nuclear gene expression. We thank Heather Issar (University of Arizona Genetics Core), Melissa Johnson, Ala Malia Leka, Keenan Morrison, Courtland Warr, Steffen Oeser (JABSOM Genomic Core Facility) and Anne Veillet (Genetic Core Facility, UH Hilo) for technical assistance, Mark Chase and two anonymous reviewers for critical comments on previous versions of the manuscript. Funding was provided by the Gordon and Betty Moore Foundation and Washington State University.

\section{Author details}

'Tropical Conservation Biology and Environmental Science, University of Hawai'i at Hilo, 200 West Kawili Street, Hilo, HI 96720, USA. '2Department of Biology, University of Florida, Gainesville, FL 32611, USA. ${ }^{3}$ Genetics Institute, University of Florida, Gainesville, FL 32610, USA. ${ }^{4}$ School of Biological Sciences, Washington State University, 339 Abelson Hall, Pullman, WA 99164-4236, USA.

Received: 7 August 2012 Accepted: 25 January 2013

Published: 9 February 2013

\section{References}

1. Savolainen V, Cowan RS, Vogler AP, Roderick GK, Lane R: Towards writing the encyclopedia of life: an introduction to DNA barcoding. Philos Trans $R$ Soc London B 2005, 360:1805-1811.

2. Hebert PDN, Cywinska A, Ball SL, de Waard JR: Biological identifications through DNA barcodes. Proc R Soc London B 2003, 270:313-321.

3. Hollingsworth PM, Graham SW, Little DP: Choosing and using a plant DNA barcode. PLoS One 2011, 6(5):e19254.

4. CBOL Plant Working Group: A DNA barcode for land plants. Proc Natl Acad Sci USA 2009, 106(31):12794-12797.

5. Chase MW, Cowan RS, Hollingsworth PM, van den Berg C, Madriñan S, Petersen G, Seberg O, Jørgensen T, Cameron KM, Carine M, et al: A proposal for a standardised protocol to barcode all land plants. Taxon 2007, 56(2):295-299.

6. Seberg O, Petersen G: How many loci does it take to DNA barcode a crocus. PLoS One 2009, 4(2):e4598.

7. China Plant BOL Group, Li D-Z, Gao L-M, Li H-T, Wang H, Ge X-J, Liu J-Q, Chen Z-D, Zhou S-L, Chen S-L, et al: Comparative analysis of a large dataset indicates that internal transcribed spacer (ITS) should be incorporated into the core barcode for seed plants. Proc Natl Acad Sci USA 2011, 108(49):19641-19646.

8. Kress WJ, Erickson DL, Jones A, Swenson NG, Perez R, Sanjur P, Bermingham E: Plant DNA barcodes and a community phylogeny of a tropical forest dynamics plot in Panama. Proc Natl Acad Sci USA 2009, 106(44):18621-18626.

9. Lahaye R, van der Bank M, Bogarin D, Warner J, Pupulin F, Gigot G, Maurin O, Duthoit S, Barraclough TG, Savolainen V: DNA barcoding the floras of biodiversity hotspots. Proc Natl Acad Sci USA 2008, 105(8):2923-2928.
10. Gonzalez MA, Baraloto C, Engel J, Mori S, Pétronelli P, Riéra B, Roger A, Thébaud C, Chave J: Identification of Amazonian trees with DNA barcodes. PLoS One 2009, 4(10):e7483

11. Maia VH, da Mata CS, Franco LO, Cardoso MA, Cardoso SRS, Hemerly AS, Ferreira PCG: DNA barcoding Bromeliaceae: achievements and pitfall. PLoS One 2012, 7(1):e29877.

12. Arca M, Hinsinger DD, Cruaud C, Tillier A, Bousquet J, Frascaria-Lacoste N: Deciduous trees and the application of universal DNA barcodes: a case study on the circumpolar Fraxinus. PLoS One 2012, 7(3):e34089.

13. Wang Q, Yu Q-S, Liu J-Q: Are nuclear loci ideal for barcoding plants? A case study of genetic delimitation of two sister species using multiple loci and multiple intraspecific individuals. J Syst Evol 2011, 49(3):182-188.

14. Wagner WL, Herbst DR, Sohmer SH: Manual of the flowering plants of Hawai'i. Honolulu: Bernice Pauahi Bishop Museum Special Publication; 1999.

15. Price JP, Clague DA: How old is the Hawaiian biota? geology and phylogeny suggest recent divergence. Proc R Soc London B 2002, 269:2429-2435.

16. Price JP: Floristic biogeography of the Hawaiian islands: influence of area, environment and paleogeography. J Biogeogr 2004, 31:487-500.

17. Costello A, Motley TJ: Phylogenetics of the Tetraplasandra group (Araliaceae) inferred from ITS, 5S-NTS, and morphology. Syst Bot 2007, 32(2):464-477.

18. Ganders FR, Berbee M, Pirseyedi M: ITS based sequence phylogeny in Bidens (Asteraceae): evidence for the continental relatives of Hawaiian and Marquesan Bidens. Syst Bot 2000, 25(1):122-133.

19. Nepokroeff M, Sytsma KJ, Wagner WL, Zimmer EA: Reconstructing ancestral patterns of colonization and dispersal in the Hawaiian understory tree genus Psychotria (Rubiaceae): a comparison of parsimony and likelihood approaches. Syst Biol 2003, 52(6):820-838.

20. Sakai AK, Weller SG, Wagner AP, Nepokroeff M, Culley TM: Adaptive radiation and evolution of breeding systems in Schiedea (Caryophyllaceae), an endemic Hawaiian genus. Ann Missouri Bot Gard 2006, 93:49-63.

21. Gemmill CEC, Allan GJ, Wagner WL, Zimmer EA: Evolution of insular pacific Pittosporum (Pittosporaceae): origin of the Hawaiian radiation. Mol Phyl Evol 2002, 22(1):31-42.

22. Howarth DG, Baum DA: Genealogical evidence of homoploid hybrid speciation in an adaptive radiation of Scaevola (Goodeniaceae) in the Hawaiian islands. Evolution 2005, 59(5):948-961.

23. Friar EA, Prince LM, Roalson EH, McGlaughlin ME, Cruse-Sanders JM, De Groot SJ, Porter JM: Ecological speciation in the east Maui-endemic Dubautia (Asteraceae) species. Evolution 2006, 60(9):1777-1792.

24. Percy DM, Garver AM, Wagner WL, James HF, Cunningham CW, Miller SE, Fleischer RC: Progressive island colonization and ancient origin of Hawaiian Metrosideros (Myrtaceae). Proc R Soc London B 2008, 275:1479-1490.

25. Givnish TJ, William KC, Mast AR, Paterson TB, Theim TJ, Hipp AL, Henss JM, Smith JF, Wood KR, Sytsma KJ: Origin, adaptive radiation and diversification of the Hawaiian lobeliads (Asterales: Campanulaceae). Proc R Soc London B 2009, 276:407-416.

26. Clark JR, Wagner WL, Roalson EH: Patterns of diversification and ancestral range reconstruction in the southeast Asian-Pacific angiosperm lineage Cyrtandra (Gesneriaceae). Mol Phyl Evol 2009, 53:982-994.

27. Palumbi S, Cipriano F, Hare MP: Predicting nuclear gene coalescence from mitochondrial data: the three-times rule. Evolution 2001, 55(5):859-868.

28. Wagner WL, Funk VA: Hawaiian biogeography: evolution on a hotspot archipelago. Washington: Smithsonian Institute Press; 1995.

29. Fleischer RC, McIntosh CE, Tarr CL: Evolution on a volcanic conveyor belt: using phylogeographic reconstructions and K-Ar-based ages of the Hawaiian islands to estimate molecular evolutionary rates. Mol Ecol 1998, 7:533-545.

30. Givnish TJ, Sytsma KJ, Smith JF, Hahn WJ: Molecular evolution, adaptive radiation, and geographic speciation in Cyanea (Campanulaceae, Lobeliodeae). In Hawaiian biogeography: evolution on a hot spot archipelago. Edited by Wagner WL, Funk VA. Washington: Smithsonian Institute Press; 1995:288-337.

31. Puritz JB, Addison JA, Toonen RJ: Next-generation phylogeography: a targeted approach for multilocus sequencing of non-model organisms. PLoS One 2012, 7(3):e34241.

32. Pertea G, Huang XQL F, Antonescu V, Sultana R, Karamycheva S, Lee $Y$, White J, Cheung F, Parvizi B, Tsai J, et al: TGIR Gene Indices clustering tools (TGICL): A software system for fast clustering of large EST datasets. Bioinformatics 2003, 19:651-652. 
33. Cummings MP, Nugent JM, Olmstead RG, Palmer JD: Phylogenetic analysis reveals five independent transfers of the chloroplast gene $r b c L$ to the mitochondrial genome in angiosperms. Curr Genet 2003, 43:131-138.

34. Clark AG: Inference of haplotypes from PCR-amplified samples of diploid populations. Mol Biol Evol 1990, 7(2):111-122.

35. Clement M, Posada D, Crandall KA: TCS: a computer program to estimate gene genealogies. Mol Ecol 2000, 9:1657-1659.

doi:10.1186/1471-2148-13-35

Cite this article as: Pillon et al:: Potential use of low-copy nuclear genes

in DNA barcoding: a comparison with plastid genes in two Hawaiian plant radiations. BMC Evolutionary Biology 2013 13:35.

\section{Submit your next manuscript to BioMed Central and take full advantage of:}

- Convenient online submission

- Thorough peer review

- No space constraints or color figure charges

- Immediate publication on acceptance

- Inclusion in PubMed, CAS, Scopus and Google Scholar

- Research which is freely available for redistribution 